\title{
Divergência genética entre cultivares comerciais de repolho quanto à preferência do pulgão-da-couve
}

\author{
Brisa do Svadeshi Cabral de Melo(1), Ervino Bleicher ${ }^{(1)}$, Cândida Hermínia Campos de Magalhães Bertini ${ }^{(1)}$ \\ e Jefté Ferreira da Silva(1)
}

\begin{abstract}
(1)Universidade Federal do Ceará, Avenida Mister Hull, s/no, Pici, CEP 60021-970 Fortaleza, Ceará. E-mail: brisa.cabral@gmail.com, ervino@ufc.br, candida@ufc.br, jefteferreira@gmail.com
\end{abstract}

Resumo - O objetivo deste trabalho foi avaliar a divergência genética entre cultivares de repolho quanto à preferência alimentar do pulgão-da-couve (Brevicoryne brassicae). O experimento foi realizado com 27 cultivares, em casa de vegetação, com determinação da preferência do afídeo em ensaios com ou sem chance de escolha. Utilizou-se o delineamento de blocos ao acaso, com 27 tratamentos e cinco repetições. Estimaram-se as distâncias generalizadas de Mahalanobis e as cultivares foram agrupadas pelo método de Tocher, com formação de sete grupos. As cultivares Chato de Quintal, Ryuho e Taishita foram as menos preferidas pelo afídeo. A distância máxima foi verificada entre as cultivares Das 4 Estações e Suki, e a mínima ocorreu entre Chato de Quintal e Astrus Plus. O número de ninfas é a variável que permite maior diferenciação entre as cultivares. Há variabilidade entre as cultivares comerciais de repolho quanto à preferência alimentar do pulgão.

Termos para indexação: Brassica oleracea, Brevicoryne brassicae, interação planta-inseto, mecanismo de resistência, preferência alimentar.

\section{Genetic divergence between cabbage commercial cultivars as to cabbage aphid preference}

\begin{abstract}
The objective of this work was to evaluate the genetic divergence between cabbage cultivars, concerning the feeding preference of cabbage aphid (Brevicoryne brassicae). The experiment was carried out with 27 cultivars, in greenhouse, where the aphid preference was determined in assays with or without choice. A randomized block design was used with 27 treatments and five replicates. Mahalanobis' generalized distances were estimated and the cultivars were grouped by Tocher's method with seven groups formed. 'Chato de Quintal', 'Ryuho', and 'Taishita' were the less preferred cultivars by the aphid. The maximum distance was observed between the cultivars Das 4 Estações and Suki, the minimal distance occurred between 'Chato de Quintal' and 'Astrus Plus'. The number of nymphs is the variable that allows the highest differentiation between cultivars. There is variability between cabbage commercial cultivars as to aphid feeding preference.

Index terms: Brassica oleracea, Brevicoryne brassicae, plant-insect interaction, resistance mechanism, feeding preference.
\end{abstract}

\section{Introdução}

A infestação de cultivos de repolho (Brassica oleracea var. capitata) pelo pulgão-da-couve (Brevicoryne brassicae L., 1758) é frequente. $\mathrm{O}$ afídeo atinge facilmente elevadas densidades, o que compromete a qualidade e produtividade da cultura (Girousse et al., 2003; Ahmad \& Aslam, 2005). A aplicação de inseticidas tem sido a principal prática utilizada para seu controle (Andrei, 2009). No entanto, ela pode causar a morte de organismos benéficos (Bacci et al., 2001), a indução da resistência no inseto-alvo (Almeida et al., 2007), impactos ambientais e a contaminação dos alimentos.
Estudos mostram que várias espécies de crucíferas apresentam resistência a insetos (Menezes Junior et al., 2005; Thuler et al., 2007; Munthali, 2009). Entretanto, os níveis de resistência a afídeos registrados em brássicas (Ellis et al., 1998; Pink et al., 2003; Pokhraj et al., 2005; Bashir, 2011) não são suficientes para assegurar que as cultivares fiquem livres de seu ataque (Collier \& Finch, 2007). Há relatos de resistência ao pulgão-da-couve nos 375 gêneros que compõem a família Brassicaceae (Ellis et al., 1998), mas a carência de fontes de resistência em genomas compatíveis compromete o sucesso da introgressão da resistência por meio do melhoramento convencional interespecífico (Bhatia et al., 2011). 
O estudo da divergência genética das populações quanto à resistência ao pulgão-da-couve é útil na seleção de progenitores para a obtenção de combinações híbridas com maior efeito heterótico e maior heterozigose, que facilitam a recuperação de genótipos superiores nas gerações segregantes (Cruz \& Regazzi, 2001; Oliveira et al., 2003).

O objetivo deste trabalho foi avaliar a divergência genética entre cultivares de repolho quanto à preferência alimentar do pulgão-da-couve (Brevicoryne brassicae).

\section{Material e Métodos}

O experimento foi realizado em casa de vegetação do Departamento de Fitotecnia da Universidade Federal do Ceará (UFC), em Fortaleza, CE, de 17/12/2010 a 10/02/2011. A temperatura média máxima foi de $37,93 \pm 1,49^{\circ} \mathrm{C}$ e mínima de $27,02 \pm 0,81^{\circ} \mathrm{C}$, tendo-se registrado $82,62 \pm 4,15 \%$ como máxima umidade relativa e 52,62 $\pm 7,08 \%$ como mínima.

Vinte sete cultivares comerciais de repolho (Tabela 1) foram semeadas em bandejas de isopor, com 128 células, em 17 e 20 de dezembro de 2010. Após 28 dias do plantio, as mudas foram transplantadas para vasos descartáveis de poliestireno $(300 \mathrm{~mL})$, com substrato constituído de húmus de minhoca, areia e vermiculita à proporção de $3: 3: 1$, respectivamente.

Cada tratamento foi representado por uma cultivar. A unidade experimental consistiu de uma planta, com quatro folhas verdadeiras totalmente expandidas. Cada planta foi infestada com cinco fêmeas ápteras e adultas de pulgões, previamente selecionadas. Os exemplares de $B$. brassicae utilizados para os ensaios provieram da criação da UFC, mantida com o repolho 'Chato de Quintal'. A cada 5 min, os pulgões eram selecionados da criação e transferidos à planta correspondente ao tratamento. Utilizou-se o delineamento experimental de blocos ao acaso, com 27 tratamentos e 5 repetições.

Avaliou-se o comportamento dos pulgões em dois ensaios, um com chance de escolha, com movimentação livre dos insetos entre os tratamentos, e outro sem chance de escolha entre as cultivares, com as plantas confinadas em minigaiolas. Cada minigaiola foi confeccionada com cano PVC de $23 \mathrm{~mm}$ de diâmetro interno. O cano foi seccionado em pedaços de $1 \mathrm{~cm}$ de altura, com área de $4,15 \mathrm{~cm}^{2}$, e foi coberto com tecido, para permitir a circulação de ar e a entrada de luz.

Após três dias da infestação, foi contado o número de adultos vivos (NAV) e de ninfas $(\mathrm{NN})$ presentes na planta. No ensaio sem chance de escolha, os adultos mortos depositavam-se no fundo das minigaiolas, o que possibilitou o registro da mortalidade (número de adultos mortos - NAM). A taxa de natalidade (TN) foi calculada por $\mathrm{NN} / 5$, em que 5 é o número inicial de pulgões.

Os dados das variáveis foram transformados em $(\mathrm{x}+0,5)^{0,5}$ e submetidos à análise de variância. As médias das cultivares, para cada variável, foram submetidas ao agrupamento proposto por Scott-Knott (Scott \& Knott, 1974) a 5\% probabilidade.

Adotou-se a metodologia desenvolvida por Mulamba \& Mock (1978), que consiste em classificar as variáveis analisadas, atribuindo-se nota crescente de acordo com as características desejáveis para o melhoramento. As variáveis de cada parcela são então ranqueadas, e o índice da soma dos postos das parcelas é obtido de acordo com as notas atribuídas. Aplicou-se o teste de comparação múltipla de Scott-Knott a esses índices, conforme a metodologia empregada por Silva \& Bleicher (2010), para a formação dos grupos.

Tabela 1. Cultivares de repolho avaliadas.

\begin{tabular}{|c|c|c|c|c|}
\hline $\mathrm{T}^{(1)}$ & Cultivar & Pol. $^{(2)}$ & Resistência & Empresa \\
\hline 1 & Louco de Verão & PL & Sem informação & Topseed \\
\hline 2 & Roxo & PL & Yellow Spot Virus & IslaPak \\
\hline 3 & Chato de Quintal & PL & Sem informações & IslaPro \\
\hline 4 & 60 Dias & PL & Sem informações & IslaPak \\
\hline 5 & Takami & $\mathrm{H}$ & Xanthomonas campestris & Feltrin \\
\hline 6 & Chato de Quintal & PL & Sem informações & Feltrin \\
\hline 7 & Taishita & $\mathrm{H}$ & X. campestris & Feltrin \\
\hline 8 & Suki & $\mathrm{H}$ & Fusarium / X. campestris & Feltrin \\
\hline 9 & Akahana & PL & X. campestris PV. Campestris & Feltrin \\
\hline 10 & Chiaki & $\mathrm{H}$ & Fusarium / X. campestris & Feltrin \\
\hline 11 & Kami & PL & X. campestris & Feltrin \\
\hline 12 & Kenzo & PL & X. campestris & Feltrin \\
\hline 13 & Louco de Verão & PL & Sem informação & Feltrin \\
\hline 14 & Roxo Gigante & PL & Sem informação & Feltrin \\
\hline 15 & Das 4 Estações & PL & Sem informação & Feltrin \\
\hline 16 & Yakko & PL & Sem informação & Feltrin \\
\hline 17 & Coração de Boi Gigante & $\mathrm{PL}$ & Sem informação & Feltrin \\
\hline 18 & 60 Dias & PL & Sem informação & Feltrin \\
\hline 19 & Ryuho & $\mathrm{H}$ & Doenças em geral & Feltrin \\
\hline 20 & Super Red (híbrido) & $\mathrm{H}$ & Sem informação & IslaPak \\
\hline 21 & Fuyutokio (híbrido) & $\mathrm{H}$ & Fusarium / Yellow Spot Virus & IslaPak \\
\hline 22 & Coração de Boi & PL & Sem informação & IslaPak \\
\hline 23 & Blue Dinasty & PL & Sem informação & Seminis \\
\hline 24 & Astrus Plus & $\mathrm{H}$ & Sem informação & Seminis \\
\hline 25 & Shinsei & PL & Sem informação & Tohoku \\
\hline 26 & Bobcat & $\mathrm{H}$ & X. campestris & Sakata \\
\hline 27 & Louco de Verão & PL & Tolerante a Xanthomonas & IslaPak \\
\hline
\end{tabular}

${ }^{(1)} \mathrm{T}$, tratamento. ${ }^{(2)}$ Pol., polinização; PL, polinização aberta; H, híbrido. 
Obteve-se a estimativa da distância de Mahalanobis $\left(D^{2}\right)$ e quantificou-se a contribuição relativa de cada variável para a divergência genética, pelo método proposto por Singh (1981). Com os dados de $\mathrm{D}^{2}$, realizou-se a separação das cultivares mais similares, pela formação de grupos com a técnica de agrupamento de Tocher.

As análises estatísticas univariadas e multivariadas foram processadas pelo programa Genes (Cruz, 2007).

\section{Resultados e Discussão}

Dois grupos de cultivares foram formados no teste com chance de escolha, de acordo com o número de adultos vivos, o número de ninfas e a taxa de natalidade (Tabela 2). As cultivares Chato de Quintal (tratamento 3), Chiaki, Ryuho, Blue Dinasty, Das 4 Estações, Taishita, 60 Dias, Suki e Bobcat foram menos preferidas pelos adultos, tendo apresentado menor número de adultos vivos. Nessas cultivares, a taxa de natalidade foi significativamente menor do que nas demais. O número de ninfas foi menor em 'Chato de Quintal' (tratamento 3), 'Chiaki', 'Ryuho', 'Blue Dinasty', 'Das 4 Estações', 'Coração de Boi Gigante', 'Taishita', '60 Dias', 'Suki', 'Takami'.

No ensaio sem chance de escolha, os grupos formados com as variáveis número de adultos vivos e número de adultos mortos não diferiram. Esse resultado decorre do uso de uma mesma quantidade de insetos para a infestação nas minigaiolas, que não possibilitam fugas. No entanto, o número de ninfas e a taxa de natalidade foram menores nas cultivares Chato de Quintal (tratamento 3), Chiaki, Ryuho, Taishita, Takami, Suki, Kenzo, Akahana, Roxo (tratamento 2), Chato de Quintal (tratamento 6), Astrus Plus e Louco de Verão (tratamento 1).

Tabela 2. Número de adultos vivos (NAV), número de adultos mortos (NAM), número de ninfas (NN) e taxa de natalidade (TN) do pulgão Brevicoryne brassicae, em 27 cultivares de repolho, em experimentos com ou sem chance de escolha ${ }^{(1)}$.

\begin{tabular}{|c|c|c|c|c|c|c|c|c|}
\hline \multirow[t]{2}{*}{ Tratamento } & \multirow[t]{2}{*}{ Cultivar } & \multicolumn{3}{|c|}{ Teste com chance de escolha } & \multicolumn{4}{|c|}{ Teste sem chance de escolha } \\
\hline & & NAV & NN & $\mathrm{TN}$ & NAV & NAM & NN & $\mathrm{TN}$ \\
\hline 3 & Chato de Quintal & $1,40 \mathrm{a}$ & $13,20 \mathrm{a}$ & $2,64 \mathrm{a}$ & $1,00 \mathrm{a}$ & $3,80 \mathrm{a}$ & $3,40 \mathrm{a}$ & $0,68 \mathrm{a}$ \\
\hline 10 & Chiaki & $1,40 \mathrm{a}$ & $10,80 \mathrm{a}$ & $2,16 \mathrm{a}$ & $2,00 \mathrm{a}$ & $2,60 \mathrm{a}$ & $9,40 \mathrm{a}$ & $1,88 \mathrm{a}$ \\
\hline 19 & Ryuho & $1,40 \mathrm{a}$ & $9,80 \mathrm{a}$ & $1,96 \mathrm{a}$ & $2,00 \mathrm{a}$ & $2,80 \mathrm{a}$ & $9,20 \mathrm{a}$ & $1,84 \mathrm{a}$ \\
\hline 23 & Blue Dinasty & $1,40 \mathrm{a}$ & $16,60 \mathrm{a}$ & $3,32 \mathrm{a}$ & $2,60 \mathrm{a}$ & $2,20 \mathrm{a}$ & $16,60 b$ & $3,32 b$ \\
\hline 15 & Das 4 Estações & $1,60 \mathrm{a}$ & $6,80 \mathrm{a}$ & $1,36 \mathrm{a}$ & $2,80 \mathrm{a}$ & $2,00 \mathrm{a}$ & $21,20 b$ & $4,24 b$ \\
\hline 17 & Coração de Boi Gigante & $1,80 \mathrm{~b}$ & $24,40 \mathrm{a}$ & $4,88 \mathrm{~b}$ & $2,40 \mathrm{a}$ & $2,40 \mathrm{a}$ & $20,40 b$ & $4,08 \mathrm{~b}$ \\
\hline 7 & Taishita & $2,00 \mathrm{a}$ & $15,60 \mathrm{a}$ & $3,12 \mathrm{a}$ & $0,60 \mathrm{a}$ & $4,00 \mathrm{a}$ & $3,20 \mathrm{a}$ & $0,64 a$ \\
\hline 4 & 60 Dias & $2,20 \mathrm{a}$ & $23,20 \mathrm{a}$ & $4,64 \mathrm{a}$ & $3,00 \mathrm{a}$ & $1,40 \mathrm{a}$ & $13,60 \mathrm{~b}$ & $2,72 \mathrm{a}$ \\
\hline 5 & Takami & $2,20 \mathrm{~b}$ & $23,80 \mathrm{a}$ & $4,76 b$ & $2,40 \mathrm{a}$ & $2,20 \mathrm{a}$ & $14,60 \mathrm{a}$ & $2,92 \mathrm{a}$ \\
\hline 8 & Suki & $2,40 \mathrm{a}$ & $18,00 \mathrm{a}$ & $3,60 \mathrm{a}$ & $1,40 \mathrm{a}$ & $3,40 \mathrm{a}$ & $10,40 \mathrm{a}$ & $2,08 \mathrm{a}$ \\
\hline 12 & Kenzo & $2,40 \mathrm{~b}$ & $30,00 \mathrm{~b}$ & $6,00 \mathrm{~b}$ & $2,00 \mathrm{a}$ & $2,20 \mathrm{a}$ & $9,60 \mathrm{a}$ & $1,92 \mathrm{a}$ \\
\hline 26 & Bobcat & $2,40 \mathrm{a}$ & $18,20 \mathrm{~b}$ & $3,64 \mathrm{a}$ & $3,20 \mathrm{a}$ & $1,60 \mathrm{a}$ & $27,60 \mathrm{~b}$ & $5,52 b$ \\
\hline 9 & Akahana & $2,60 \mathrm{~b}$ & $30,80 \mathrm{~b}$ & $6,16 b$ & $2,40 \mathrm{a}$ & $2,00 \mathrm{a}$ & $11,00 \mathrm{a}$ & $2,20 \mathrm{a}$ \\
\hline 11 & Kami & $2,60 \mathrm{~b}$ & $26,00 \mathrm{~b}$ & $5,20 \mathrm{~b}$ & $3,20 \mathrm{a}$ & $1,40 \mathrm{a}$ & $17,00 \mathrm{~b}$ & $3,40 \mathrm{~b}$ \\
\hline 18 & 60 Dias & $2,60 \mathrm{~b}$ & $26,00 \mathrm{~b}$ & $5,20 \mathrm{~b}$ & $2,40 \mathrm{a}$ & $2,40 \mathrm{a}$ & $21,40 \mathrm{~b}$ & $4,28 b$ \\
\hline 2 & Roxo & $2,80 \mathrm{~b}$ & $23,60 \mathrm{~b}$ & $4,72 b$ & $2,40 \mathrm{a}$ & $1,80 \mathrm{a}$ & $12,20 \mathrm{a}$ & $2,44 a$ \\
\hline 6 & Chato de Quintal & $2,80 \mathrm{~b}$ & $29,80 b$ & $5,96 \mathrm{~b}$ & $2,00 \mathrm{a}$ & $2,80 \mathrm{a}$ & $9,40 \mathrm{a}$ & $1,88 \mathrm{a}$ \\
\hline 20 & Super Red & $2,80 \mathrm{~b}$ & $23,00 \mathrm{~b}$ & $4,60 \mathrm{~b}$ & $2,20 \mathrm{a}$ & $2,40 \mathrm{a}$ & $17,00 \mathrm{~b}$ & $3,40 \mathrm{~b}$ \\
\hline 13 & Louco de Verão & $3,00 \mathrm{~b}$ & $33,00 \mathrm{~b}$ & $6,60 \mathrm{~b}$ & $3,20 \mathrm{a}$ & $1,60 \mathrm{a}$ & $23,20 b$ & $4,64 b$ \\
\hline 14 & Roxo Gigante & $3,00 \mathrm{~b}$ & $42,00 \mathrm{~b}$ & $8,40 \mathrm{~b}$ & $2,60 \mathrm{a}$ & $2,20 \mathrm{a}$ & $18,80 \mathrm{~b}$ & $3,76 b$ \\
\hline 21 & Fuyutokio & $3,00 \mathrm{~b}$ & $29,00 \mathrm{~b}$ & $5,80 \mathrm{~b}$ & $4,20 \mathrm{a}$ & $0,60 \mathrm{a}$ & $26,40 \mathrm{~b}$ & $5,28 b$ \\
\hline 24 & Astrus Plus & $3,00 \mathrm{~b}$ & $23,60 \mathrm{~b}$ & $4,72 b$ & $2,60 \mathrm{a}$ & $2,20 \mathrm{a}$ & $15,00 \mathrm{a}$ & $3,00 \mathrm{a}$ \\
\hline 27 & Louco de Verão & $3,20 b$ & $28,40 b$ & $5,68 b$ & $3,00 \mathrm{a}$ & $1,40 \mathrm{a}$ & $13,60 \mathrm{~b}$ & $2,72 \mathrm{a}$ \\
\hline 22 & Coração de Boi & $3,40 \mathrm{~b}$ & $26,80 \mathrm{~b}$ & $5,36 \mathrm{~b}$ & $3,60 \mathrm{a}$ & $0,60 \mathrm{a}$ & $25,20 b$ & $5,04 \mathrm{~b}$ \\
\hline 16 & Yakko & $3,60 \mathrm{~b}$ & $33,40 \mathrm{~b}$ & $6,68 b$ & $2,80 \mathrm{a}$ & $2,00 \mathrm{a}$ & $20,20 b$ & $4,04 \mathrm{~b}$ \\
\hline 25 & Shinsei & $3,60 \mathrm{~b}$ & $33,80 \mathrm{~b}$ & $6,76 b$ & $3,40 \mathrm{a}$ & $1,40 \mathrm{a}$ & $18,40 \mathrm{~b}$ & $3,68 \mathrm{~b}$ \\
\hline 1 & Louco de Verão & $4,20 \mathrm{~b}$ & $42,80 \mathrm{~b}$ & $8,56 \mathrm{~b}$ & $2,00 \mathrm{a}$ & $2,80 \mathrm{a}$ & $11,00 \mathrm{a}$ & $2,20 \mathrm{a}$ \\
\hline Média & & 24,53 & 24,99 & 4,91 & 2,54 & 2,14 & 16,07 & 3,12 \\
\hline CV $(\%)$ & & 20,14 & 28,13 & 25,54 & 27,12 & 28,88 & 39,99 & 33,42 \\
\hline
\end{tabular}

${ }^{(1)}$ Médias seguidas de letras iguais não diferem entre si, pelo teste de Scott-Knott, a 5\% de probabilidade. 
Munthali (2009), em estudo com outras cultivares de repolho, verificou que a capacidade reprodutiva de $B$. brassicae é menor se a cultivar tem algum efeito antibiótico sobre a praga, ou seja, a variedade pode afetar a capacidade reprodutiva do pulgão. Em testes sem chance de escolha, considera-se que o pulgão pode superar os efeitos de possíveis substâncias deterrentes (Bhatia et al., 2011) e atacar a planta mesmo sem preferi-la. Neste caso, não é possível determinar se os efeitos fisiológicos na população do inseto são resultantes da ação de substâncias tóxicas da planta (antibiose), ou da alimentação deficiente decorrente da não preferência (antixenose). No presente trabalho, no entanto, observou-se que, em algumas cultivares, o pulgão $B$. brassicae exibiu o mesmo comportamento, independentemente da condição de confinamento.

As cultivares Chato de Quintal (tratamento 3), Taishita, Suki, Chiaki e Ryuho tiveram menor número médio de adultos vivos no experimento com chance de escolha, e foram menos preferidas pelo afídeo.
Também apresentaram menor número de ninfas e taxa de natalidade nos experimentos com e sem chance de escolha. Ao associar a soma de postos (Mulamba \& Mock, 1978) ao método de agrupamento de Scott-Knott, foi possível reunir as cultivares analisadas em três grupos (Tabela 3), classificados como moderadamente resistente, suscetível e altamente suscetível.

As seguintes cultivares apresentaram menor quantidade de pulgão de acordo com a soma de postos: Chato de Quintal (tratamento 3), Ryuho, Taishita, Chiaki, Suki. Nenhuma das nove cultivares avaliadas por Munthali (2009), na África, apresentou-se totalmente livre de $B$. brassicae, o que também ocorreu no presente trabalho.

Foi possível verificar que a preferência do pulgão pode diferir em uma mesma cultivar, comercializada por empresas diferentes: Chato de Quintal (tratamentos 3 e 6); Repolho roxo (tratamentos 2 e 14); e Louco de verão (tratamentos 1, 13 e 27). Essas diferenças no grau de resistência de uma mesma cultivar podem

Tabela 3. Classificação de 27 cultivares de repolho, quanto à preferência do pulgão Brevicoryne brassicae, de acordo com a classificação de Mulamba \& Mock (1978), em experimentos com ou sem chance de escolha.

\begin{tabular}{|c|c|c|c|c|c|c|c|c|c|c|}
\hline \multirow[t]{2}{*}{ Tratamento } & \multirow[t]{2}{*}{ Cultivar } & \multicolumn{4}{|c|}{ Sem chance de escolha } & \multicolumn{3}{|c|}{ Com chance de escolha } & \multirow[t]{2}{*}{ Posição(1) } & \multirow[t]{2}{*}{ Classificação } \\
\hline & & NAV & NAM & NN & $\mathrm{TN}$ & NAV & $\mathrm{NN}$ & $\mathrm{TN}$ & & \\
\hline 3 & Chato de Quintal & 2 & 2 & 2 & 2 & 3 & 4 & 4 & $19 a$ & Moderadamente resistente \\
\hline 19 & Ryuho & 4 & 4 & 3 & 3 & 1 & 2 & 2 & $19 \mathrm{a}$ & Moderadamente resistente \\
\hline 7 & Taishita & 1 & 1 & 1 & 1 & 7 & 5 & 5 & $21 \mathrm{a}$ & Moderadamente resistente \\
\hline 10 & Chiaki & 6 & 7 & 5 & 4 & 2 & 3 & 3 & $30 \mathrm{a}$ & Moderadamente resistente \\
\hline 8 & Suki & 3 & 3 & 7 & 7 & 10 & 7 & 7 & $44 \mathrm{a}$ & Moderadamente resistente \\
\hline 23 & Blue Dynasty & 16 & 11 & 14 & 14 & 4 & 6 & 6 & $71 b$ & Suscetível \\
\hline 6 & Chato de Quintal & 5 & 5 & 4 & 5 & 18 & 20 & 20 & $77 b$ & Suscetível \\
\hline 20 & Super Red & 9 & 8 & 16 & 16 & 16 & 9 & 9 & $83 b$ & Suscetível \\
\hline 5 & Takami & 12 & 12 & 12 & 12 & 9 & 13 & 13 & $83 b$ & Suscetível \\
\hline 15 & Das 4 Estações & 19 & 16 & 21 & 21 & 5 & 1 & 1 & $84 b$ & Suscetível \\
\hline 12 & Kenzo & 7 & 13 & 6 & 6 & 12 & 21 & 21 & $86 b$ & Suscetível \\
\hline 2 & Roxo & 11 & 19 & 10 & 10 & 17 & 11 & 12 & $90 \mathrm{~b}$ & Suscetível \\
\hline 4 & 60 Dias & 20 & 22 & 11 & 11 & 8 & 10 & 10 & $92 b$ & Suscetível \\
\hline 17 & Coração de Boi Gigante & 13 & 9 & 20 & 20 & 6 & 14 & 14 & $96 b$ & Suscetível \\
\hline 24 & Astrus Plus & 15 & 14 & 13 & 13 & 19 & 12 & 11 & $97 b$ & Suscetível \\
\hline 9 & Akahana & 10 & 17 & 9 & 8 & 15 & 22 & 22 & $103 b$ & Suscetível \\
\hline 1 & Louco de Verão & 8 & 6 & 8 & 9 & 27 & 27 & 27 & $112 b$ & Suscetível \\
\hline 18 & 60 Dias & 14 & 10 & 22 & 22 & 14 & 16 & 16 & $114 b$ & Suscetível \\
\hline 11 & Kami & 21 & 23 & 15 & 15 & 13 & 15 & 15 & $117 \mathrm{~b}$ & Suscetível \\
\hline 26 & Bobcat & 23 & 20 & 26 & 26 & 11 & 8 & 8 & $122 b$ & Suscetível \\
\hline 14 & Roxo Gigante & 17 & 15 & 18 & 18 & 22 & 26 & 26 & $142 \mathrm{c}$ & Altamente suscetível \\
\hline 16 & Yakko & 18 & 18 & 19 & 19 & 25 & 24 & 24 & $147 \mathrm{c}$ & Altamente suscetível \\
\hline 13 & Louco de Verão & 22 & 21 & 23 & 23 & 21 & 23 & 23 & $156 \mathrm{c}$ & Altamente suscetível \\
\hline 22 & Coração de Boi & 25 & 26 & 24 & 24 & 24 & 17 & 17 & $157 \mathrm{c}$ & Altamente suscetível \\
\hline 25 & Shinsei & 24 & 24 & 17 & 17 & 26 & 25 & 25 & $158 \mathrm{c}$ & Altamente suscetível \\
\hline 21 & Fuyutokio & 27 & 27 & 25 & 25 & 20 & 19 & 19 & $162 \mathrm{c}$ & Altamente suscetível \\
\hline 27 & Louco de Verão & 26 & 25 & 27 & 27 & 23 & 18 & 18 & $164 \mathrm{c}$ & Altamente suscetível \\
\hline
\end{tabular}

${ }^{(1)}$ Médias seguidas por letras iguais não diferem entre si, pelo teste de Scott-Knott, a 1\% de probabilidade. CV = 20,32\%. NAV, número de adultos vivos; NAM, número de adultos mortos; NN, número de ninfas; $\mathrm{TN}$, taxa de natalidade. 
ter ocorrido pelo processo de seleção realizado por cada empresa de sementes. Fatores ambientais também devem ser considerados, por sua interferência na expressão fenotípica das cultivares, o que tem influência direta na seleção.

A amplitude máxima em $\mathrm{D}^{2}$ foi observada entre os repolhos 'Das 4 Estações' e 'Suki' (Tabela 4). Essas cultivares foram as mais divergentes quanto à resistência ao pulgão, considerando-se as variáveis avaliadas.

Cerca de $60 \%$ das maiores distâncias $\mathrm{D}^{2}$ ocorreram quando as cultivares foram comparadas a 'Das 4 Estações'. No entanto, somente duas das cultivares moderadamente resistentes (Taishita e Suki) apresentaram maiores valores de $\mathrm{D}^{2}$ na comparação com 'Das 4 Estações', classificada como sucetível. As outras três cultivares classificadas como moderadamente resistentes, Chato de Quintal (tratamento 3), Chiaki

Tabela 4. Medidas de dissimilaridade genética entre 27 cultivares de repolho, quanto à preferência do pulgão Brevicoryne brassicae.

\begin{tabular}{|c|c|c|c|c|c|}
\hline \multirow[t]{2}{*}{ Tratamento } & \multirow[t]{2}{*}{ Cultivar } & \multicolumn{4}{|c|}{ Distância $\mathrm{D}^{2}$ entre cultivares } \\
\hline & & Menor & Cultivar & Maior & Cultivar \\
\hline 1 & Louco de Verão & 1,268 & 16 & 10,603 & 15 \\
\hline 2 & Roxo & 0,994 & 11 & 6,576 & 8 \\
\hline 3 & Chato de Quintal & 1,747 & 7 & 9,923 & 22 \\
\hline 4 & 60 Dias & 1,217 & 2 & 9,507 & 8 \\
\hline 5 & Takami F1 & 0,588 & 9 & 7,944 & 15 \\
\hline 6 & Chato de Quintal & 0,514 & 24 & 8,782 & 15 \\
\hline 7 & Taishita F1 & 0,996 & 8 & 10,024 & 15 \\
\hline 8 & Suki F1 & 0,996 & 7 & 12,751 & 15 \\
\hline 9 & Akahana & 0,588 & 5 & 9,640 & 15 \\
\hline 10 & Chiaki F1 & 1,023 & 19 & 8,505 & 22 \\
\hline 11 & Kami & 0,605 & 9 & 7,362 & 8 \\
\hline 12 & Kenzo & 0,817 & 5 & 12,402 & 15 \\
\hline 13 & Louco de Verão & 0,553 & 25 & 9,509 & 15 \\
\hline 14 & Roxo Gigante & 1,547 & 13 & 12,623 & 15 \\
\hline 15 & Das 4 Estações & 2,907 & 10 & 12,751 & 8 \\
\hline 16 & Yakko & 0,802 & 20 & 7,069 & 15 \\
\hline 17 & Coração de Boi Gigante & 1,437 & 18 & 7,756 & 8 \\
\hline 18 & 60 Dias & 0,809 & 13 & 9,303 & 15 \\
\hline 19 & Ryuho & 1,023 & 10 & 8,471 & 22 \\
\hline 20 & Super Red & 0,802 & 16 & 5,775 & 15 \\
\hline 21 & Fuyutokio & 0,927 & 27 & 9,769 & 15 \\
\hline 22 & Coração de Boi & 0,797 & 27 & 10,145 & 15 \\
\hline 23 & Blue Dinasty & 1,065 & 10 & 9,248 & 8 \\
\hline 24 & Astrus Plus & 0,514 & 6 & 7,836 & 15 \\
\hline 25 & Shinsei & 0,553 & 13 & 0,156 & 15 \\
\hline 26 & Bobcat & 1,287 & 18 & 7,195 & 3 \\
\hline 27 & Louco de Verão & 0,797 & 22 & 8,722 & 3 \\
\hline Menor distâ & ância geral & 0,514 & 6 e 24 & - & - \\
\hline Maior distâ & ncia geral & - & - & 12,751 & 8 e 15 \\
\hline
\end{tabular}

e Ryuho, foram as mais dissimilares na comparação com 'Coração de Boi' (altamente sucetível) (Tabela 4). Com base nesses dados, os híbridos 'Taishita', 'Suki', 'Chiaki' e 'Ryuho' podem compor fontes de resistência a $B$. brassicae, a partir de populações segregantes.

Verificou-se distância mínima entre as 'Chato de Quintal' (tratamento 6) e 'Astrus Plus'. Por comporem o mesmo grupo formado pelo teste de Scott-Knott, e de acordo com o ranqueamento das parcelas (Tabela 3), já se esperava pequena distância entre essas cultivares.

O método de otimização de Tocher, com base na distância de Mahalanobis, distribuiu as cultivares em sete grupos (Tabela 5). As cultivares moderadamente resistentes foram distribuídas em dois grupos: grupo 2, com Taishita, Suki, e Chato de Quintal; e grupo 3, com Chiaki e Ryuho (Tabela 5). Os integrantes do grupo 2 e os do 3 mantiveram as menores distâncias entre si. As cultivares ranqueadas e separadas pelo teste de Scott-Knott nos grupos suscetível e altamente suscetível compuseram os demais grupos formados pelo método de Tocher.

Broekgaarden et al. (2008) verificaram que a variação intraespecífica em repolho, quanto à suscetibilidade ao pulgão, ocorre em razão da diferença na regulação da expressão gênica entre as cultivares.

Cada um dos grupos 5, 6 e 7 contêm um exemplar de 'Das Quatro Estações', 'Roxo Gigante' (tratamento 14) e 'Louco de Verão' (tratamento 1). As maiores distâncias $\mathrm{D}^{2}$ foram verificadas na comparação entre Roxo

Tabela 5. Agrupamento das 27 cultivares de repolho, avaliadas pelo método de otimização de Tocher, com base na dissimilaridade genética quanto à resistência ao pulgão Brevicoryne brassicae, expressa pela distância de Mahalanobis.

\begin{tabular}{lcc}
\hline Grupo & Cultivares & Distâncias médias \\
\hline 1 & Chato de Quintal (6), Astrus Plus (24), 60 Dias & 1,995 \\
& (18), Louco de Verão (13), Shinsei (25), Kami \\
& (11), Yakko (16), Super Red (20), Takami \\
& F1(5), Akahana (9), Roxo (2), Louco de Verão \\
& (27), Fuyutokio (21), Bobcat (26), Coração de \\
& Boi (22), Kenzo (12) \\
3 & Taishita F1(7), Suki F1(8), Chato de Quintal (3) & 2,193 \\
3 & Chiaki F1(10), Ryuho (híbrido) (19), Blue & 2,152 \\
4 & Dynasty (23), Coração de Boi Gigante (17) & 0,000 \\
5 & 60 Dias & 0,000 \\
6 & Das 4 Estações (15) & 0,000 \\
7 & Roxo Gigante (14) & 0,000 \\
\hline
\end{tabular}

${ }^{(1)}$ Médias intragrupo pela distância de Mahalanobis.

Pesq. agropec. bras., Brasília, v.48, n.5, p.459-465, maio 2013 DOI: 10.1590/S0100-204X2013000500001 
Gigante (tratamento 14), no grupo 6, e Louco de verão (tratamento 1), no grupo 7, com 'Das Quatro Estações', no grupo 5 (Tabela 5).

As cultivares Chato de Quintal (tratamento 3), Roxo Gigante (tratamento 14) e Louco de Verão (tratamento 1) também foram agrupadas em grupos distintos pelo teste de Scott-Knott (Tabela 3). No entanto, os repolhos '60 Dias' (tratamentos 18 e 4) encontram-se em grupos dissimilares, apesar de o teste de Scott-Knott não as ter separado. As maiores distâncias médias foram obtidas entre os grupos 5 e 6 , e 5 e 7 (Tabela 6).

Quanto à importância relativa das variáveis utilizadas para a avaliação da dissimilaridade genética, o número de ninfas foi a que mais influenciou a distância generalizada de Mahalanobis (Tabela 7), tanto nos ensaios sem chance de escolha como nos com chance de escolha. Resultados semelhantes foram observados por Broekgaarden et al. (2008).

Tabela 6. Distâncias médias, dentro de e entre grupos formados pelas 27 cultivares de repolho, de acordo com o agrupamento de otimização de Tocher, quanto à resistência ao pulgão Brevicoryne brassicae.

\begin{tabular}{lccccccc}
\hline Grupo & 1 & 2 & 3 & 4 & 5 & 6 & 7 \\
\hline 1 & 1,995 & 6,178 & 4,456 & 3,347 & 8,346 & 3,108 & 3,020 \\
2 & - & 2,193 & 5,918 & 7,305 & 9,706 & 6,460 & 7,149 \\
3 & - & - & 2,152 & 3,835 & 4,969 & 5,780 & 7,289 \\
4 & - & - & - & 0,000 & 5,002 & 4,984 & 4,668 \\
5 & - & - & - & - & 0,000 & 12,623 & 10,603 \\
6 & - & - & - & - & - & 0,000 & 3,122 \\
7 & - & - & - & - & - & - & 0,000 \\
\hline
\end{tabular}

Tabela 7. Contribuição relativa das variáveis para a avaliação da divergência entre 27 cultivares de repolho, quanto à resistência ao pulgão Brevicoryne brassicae, de acordo com Singh (1981).

\begin{tabular}{lc}
\hline Variável & Contribuição relativa (\%) \\
\hline Número de ninfas & Sem chance de escolha \\
Número de adultos vivos & 16,345 \\
Número de adultos mortos & 0,092 \\
Taxa de natalidade & 2,893 \\
\hline & 11,784 \\
Número de ninfas & Com chance de escolha \\
Número de adultos vivos & 36,109 \\
Taxa de natalidade & 2,156 \\
\hline
\end{tabular}

Pesq. agropec. bras., Brasília, v.48, n.5, p.459-465, maio 2013 DOI: 10.1590/S0100-204X2013000500001

\section{Conclusões}

1. Há divergência genética entre as cultivares comerciais de repolho, quanto à preferência alimentar de Brevicoryne brassicae.

2. As cultivares Chato de Quintal, Taishita e Ryuho são menos infestadas pelo pulgão-da-couve; e os híbridos Taishita, Suki, Chiaki e Ryuho podem compor fontes de resistência a $B$. brassicae, a partir de populações segregantes.

3. O número de ninfas é a variável que mais contribui para a avaliação da dissimilaridade entre as cultivares.

\section{Referências}

AHMAD, M.; ASLAM, M. Resistance of cabbage aphid, Brevicoryne brassicae (Linnaeus) to endosulfan, organophosphates and synthetic pyrethroids. Pakistan Journal of Zoology, v.37, p.293-295, 2005.

ALMEIDA, G.D. de; PRATISSOLI, D.; POLANCZYK, R.A.; HOLTZ, A.M.; VICENTINI, V.B. Determinação das concentração letal média (CL50) de Beauveria bassiana para o controle de Brevicoryne brassicae. Idesia (Arica), v.25, p.69-72, 2007. DOI: 10.4067/S0718-34292007000200009.

ANDREI, E. (Coord.). Compêndio de defensivos agrícolas: guia prático de produtos fitossanitários para uso agrícola. 8.ed. São Paulo: Andrei, 2009. 1378p.

BACCI, L.; PICANÇO, M.C.; GUSMÃO, M.R.; CRESPO, A.L.B.; PEREIRA, E.J.G. Seletividade de inseticidas a Brevicoryne brassicae (L.) (Hemiptera: Aphididae) e ao predador Doru luteipes (Scudder) (Dermaptera: Forficulidae). Neotropical Entomology, v.30, p.707-713, 2001. DOI: 10.1590/ S1519-566X2001000400028.

BASHIR, F. Effects of the food plants on the bionomics of cabbage aphids, Brevicoryne brassicae (L.). 2011. 106p. Dissertation (Master) - The University of Kashmir, Srinagar.

BHATIA, V.; UNIYAL, P.L.; BHATTACHARYA, R. Aphid resistance in Brassica crops: challenges, biotechnological progress and emerging possibilities. Biotechnology Advances, v.29, p.879-888, 2011. DOI: 10.1016/j.biotechadv.2011.07.005.

BROEKGAARDEN, C.; POELMAN, E.H.; STEENHUIS, G.; VOORRIPS, R.E.; DICKE, M.; VOSMAN, B. Responses of Brassica oleracea cultivars to infestation by the aphid Brevicoryne brassicae: an ecological and molecular approach. Plant, Cell and Environment, v.31, p.1592-1605, 2008. DOI: 10.1111/j.1365-304 0.2008.01871.x.

COLLIER, R.H.; FINCH, S. IPM case studies: Brassicas. In: EMDEN, H.F. van; HARRINGTON, R. (Ed.). Aphids as crop pests. Wallingford: CABI Publishing, 2007. p.549-569. DOI: 10.1079/9780851998190.0549.

CRUZ, C.D. Programa Genes: estatística experimental e matrizes. Viçosa: Ed. UFV, 2007. 285p. 
CRUZ, C.D.; REGAZZI, A.J. Modelos biométricos aplicados ao melhoramento genético. Viçosa: Ed. UFV, 2001. 390p.

ELLIS, P.R.; PINK, D.A.C.; PHELPS, K.; JUKES, P.L.; PINNEGAR, A.E. Evaluation of a core collection of Brassica oleracea accessions for resistence to Brevicoryne brassicae, the cabbage aphid. Euphytica, v.103, p.149-160, 1998. DOI: 10.1023/A:1018342101069.

GIROUSSE, C.; FAUCHER, M.; KLEINPETER, C.; BONNEMAIN, J.L. Dissection of the effects of the aphid Acyrthosiphon pisum feeding on assimilate partitioning in Medicago sativa. New Phytologist, v.157, p.83-92, 2003. DOI: 10.1046/j.1469-8137.2003.00659.x.

MENEZES JUNIOR, A.O.; MIKAMI, A.Y.; IDE, A.K.; VENTURA, M.U. Feeding preferences of Microtheca punctigera (Achard) (Coleoptera: Chrysomelidae) for some Brassicaceae plants in multiple-choice assays. Scientia Agricola, v.62, p.72-75, 2005. DOI: 10.1590/S0103-90162005000100014.

MULAMBA, N.N.; MOCK, J.J. Improvement of yield potential of the method Eto Blanco maize (Zea mays L.) population by breeding for plant traits. Egyptian Journal of Genetics and Cytology, v.7, p.40-51,1978.

MUNTHALI, D.C. Evaluation of cabbage varieties for resistance to the cabbage aphid. African Entomology, v.17, p.1-7, 2009. DOI: 10.4001/003.017.0101.

OLIVEIRA, F.J. de; ANUNCIAÇÃO FILHO, J. da; BASTOS, G.Q.; REIS, O.V. dos. Divergência genética entre cultivares de caupi. Pesquisa Agropecuária Brasileira, v.38, p.605-611, 2003. DOI: 10.1590/S0100-204X2003000500008.
PINK, D.A.C.; KIFT, N.B.; ELLIS, P.R.; MCCLEMENT, S.J.; LYNN, J; TATCHELL, G.M. Genetic control of resistance to the aphid Brevicoryne brassicae in the wild species Brassica fruticulosa. Plant Breeding, v.122, p.24-29, 2003. DOI: 10.1046/j. 1439-0523.2003.00777.x.

POKHRAJ, P.; GANGULI, R.N.; GANGULI, J.; DUBEY, V.K. Pest succession in cabbage at Raipur, Chhattisgarh (India). Journal of Applied Zoological Researches, v.16, p.28-29, 2005.

RIBEIRO, N.D.; LONDERO, P.M.G.; HOFFMANN JUNIOR, L.; POERSCH, N.L.; CARGNELUTTI FILHO, A. Dissimilaridade genética para teor de proteína e fibra em grãos de feijão dos grupos preto e de cor. Revista Brasileira de Agrociência, v.11, p.167-173, 2005.

SCOTT, A.J.; KNOTT, M. A cluster analysis method for grouping means in the analysis of variance. Biometrics, v.30, p.507-512, 1974. DOI: $10.2307 / 2529204$.

SILVA, J.F. da; BLEICHER, E. Resistência de genótipos de feijao-de-corda ao pulgão-preto. Pesquisa Agropecuária Brasileira, v.45, p.1089-1094, 2010. DOI: 10.1590/ S0100-204X2010001000006.

SINGH, D. The relative importance of characters affecting genetic divergence. Indian Journal of Genetics and Plant Breeding, v.41, p.237-245, 1981.

THULER, R.T.; BERTOLI, S.A. de; HOFFMANN-CAMPO, C.B. Classificação de cultivares de brássicas com relação à resistência à traça-das-crucíferas e à presença de glucosinolatos. Pesquisa Agropecuária Brasileira, v.42, p.467-474, 2007. DOI: 10.1590/ S0100-204X2007000400003.

Recebido em 6 de dezembro de 2012 e aprovado em 29 de abril de 2013 